\title{
Atividades antiúlcera e antioxidante Baccharis trimera (Less) DC (Asteraceae)
}

\author{
Larissa Funabashi de Toledo Dias, Elisângela Severina de Melo, Leandro Santoro Hernandes, \\ Elfriede M. Bacchi*
}

\author{
Faculdade de Ciências Farmacêuticas, Universidade de São Paulo, Av. Lineu Prestes, 580, \\ 05508-900 São Paulo-SP, Brasil
}

\begin{abstract}
RESUMO: A “carqueja”, Baccharis trimera (Less) DC (Asteraceae), é uma espécie vegetal característica de regiões tropicais, muito utilizada na medicina popular como antiinflamatória, hipoglicemiante e em tratamento de problemas digestivos. A avaliação da atividade antiúlcera do extrato bruto liofilizado e do extrato liofilizado da "resina" (porção que durante a concentração dos extratos ficava depositada no fundo do recipiente com aspecto viscoso e pegajoso) foi realizada através de indução aguda por etanol acidificado. O extrato bruto liofilizado, na dose de $400 \mathrm{mg} /$ $\mathrm{kg}$, reduziu a área de lesão em $90 \%, 200 \mathrm{mg} / \mathrm{kg}, 87 \%, 100 \mathrm{mg} / \mathrm{kg}, 66 \%$ e o fármaco controle (lansoprazol), 66\%. O extrato liofilizado da "resina", administrado na dose de $400 \mathrm{mg} / \mathrm{kg}$, reduziu a área de lesão em 82\%, $200 \mathrm{mg} / \mathrm{kg}, 82 \%, 100 \mathrm{mg} / \mathrm{kg}, 53 \%$ e o fármaco controle (lansoprazol), 70\%. A atividade antioxidante foi ensaiada com extrato bruto liofilizado, extrato liofilizado da "resina", pó da droga e frações clorofórmica, acetato de etila, etanol e etanol 50\% através do método que reduz o radical 2,2'-difenil-1-picril-hidrazil (DPPH), permitindo após o equilíbrio da reação, calcular a quantidade de antioxidante gasta para reduzir $50 \%$ do DPPH, apresentando resultado evidente, comparado à vitamina $\mathrm{E}$. Não foram verificados sinais de alteração aparente no ensaio de toxicidade na dose única de $5 \mathrm{~g} / \mathrm{kg}$, em camundongos.
\end{abstract}

Unitermos: Baccharis trimera, carqueja, anti-inflamatório, hipoglicemiante, antiúlcera, problemas digestivos.

\begin{abstract}
Antiulcerogenic and antioxidant activities of Baccharis trimera (Less) DC (Asteraceae)”. Baccharis trimera (Less) DC (Asteraceae) is a medicinal Brazilian plant well-known by "carqueja". Natural from tropical regions, used as home-made medicine as anti-inflammatory, hypoglycemiant and for the treatment of digestive problems. The evaluation of the antiulcer activity of the extract and the "resin" (portion which during the extracts concentration was settled at the bottom of the recipient, showing a viscous and clammy aspect), was accomplished through the acute induction by acidified ethanol. The lyophilized extract, at a dose of $400 \mathrm{mg} / \mathrm{kg}$, reduced the lesion area at $90 \% ; 200 \mathrm{mg} / \mathrm{kg}$, at $87 \% ; 100 \mathrm{mg} / \mathrm{kg}$, at $66 \%$; and the control (lansoprazol) at $66 \%$. The "resin" administered at the $400 \mathrm{mg} / \mathrm{kg}$ dose reduced the lesion area at $82 \% ; 200 \mathrm{mg} / \mathrm{kg}$, at $82 \%$, $100 \mathrm{mg} / \mathrm{kg}$, at $53 \%$ and the control (lansoprazol), at $70 \%$. The antioxidant activity of the lyophilized extract, of the "resin" of the powdered drug, of the chloroform, ethyl acetate, ethanol and 50\% ethanol fractions was tested following the method which reduces the 2,2-diphenyl-1-picrylhydrazyl (DPPH) radical, permitting after the reaction balance, to calculate the amount of antioxidant spent to reduce $50 \%$ of the DPPH. The result was meaningful, when compared with the vitamin E result. The acute toxicity test performed in mice showed no apparent alteration.
\end{abstract}

Keywords: Baccharis trimera, carqueja, anti-inflammatory, hypoglycemiant, antiulcer, digestive problems.

\section{INTRODUÇÃO}

Baccharis trimera (Less) DC., popularmente conhecida como carqueja é usada para o tratamento de várias doenças, atribuindo-lhe propriedades tônicas, estomáquicas, febrífugas e, principalmente, em problemas hepáticos e contra disfunções estomacais e intestinais, além das propriedades antiinflamatórias e digestivas (Biavatti et al., 2007; Agra et al., 2007, 2008). Seu primeiro registro no país informava sobre o tratamento da esterilidade feminina e impotência masculina (Lorenzi, 2002).

As espécies do gênero Baccharis são tradicionalmente usadas como uma fonte terapêutica para o tratamento de diversos distúrbios relacionados à saúde do homem (Jakupovic et al., 1990; Ruiz et al., 2008) e apresentam diversas utilidades, dependendo da espécie, sendo usadas em perfumaria, como "terapêutica sem efeitos tóxicos”, sendo espécies utilizadas como antireumáticas, entre outros usos (Queiroga \& Ferracine, 
1996). Gamberini et al. (1991) relatam que o extrato aquoso de Baccharis triptera Mart, (Asteraceae), inibiu a secreção e a hiperacidez gástricas e Gené et al. (1992) estudaram em ratos os efeitos antiinflamatórios dos extratos aquosos de três espécies do gênero Baccharis. Os efeitos analgésico e antiinflamatório observados devemse, principalmente, a um complexo de saponinas que tem como componente majoritário o ácido equinocístico (Gené et al., 1996). Baggio et al. (2003) descrevem o efeito gastroprotetor, a baixa toxicidade, e o aumento da motilidade intestinal em ratos de Baccharis illinita DC (Asteraceae).

Simões-Pires et al. (2005) isolaram e identificaram compostos antioxidantes de extratos aquosos de Baccharis trimera, B.crispa, e B.usterii por HPLCUV-MS/MS através do radical DPPH/TLC.

Os extratos hidroalcoólico e aquoso de Baccharis trimera (Less) DC foram comparados por Melo \& Petrovick (2000) através de métodos físico-químicos e testes sensoriais e realizado o controle de qualidade com diferentes sistemas cromatográficos, usando como substância padrão a quercetina.

Silva et al. (2006), descrevem que não foram observadas diferenças no conteúdo de flavonóides em B. trimera (Less) DC nativas e cultivadas e colhidas em estações secas ou úmidas, no período entre de março de 2003 e fevereiro de 2004, no município de Lavras, MG. Os flavonóides eupafolina, quercetina, luteolina, nepelina, apigenina, hispidulina, quercetina, eupatorina, genkwanina, cirsimaritina, rutina, cirsiliol, genkwanina, cirsimaritina, canferol, eupatrina, eriodictiol, 5- $\mathrm{OH}-$ 6,7,3,4-OMe flavona, 5,6-OH-7,3',4'-OMe flavona e 5,7,3,4-OH-3-O-ramnosil-glicosil flavona foram isolados de $B$.trimera (Soicke \& Leng-Peschlow, 1987; Verdi et al., 2005; Borella et al., 2006).

Nakasugi \& Komai (1998), descrevem os efeitos antimutagênicos e a baixa toxicidade de Baccharis trimera (Less) DC a partir da fração metanólica purificada. Efeitos vasodilatador e relaxante da musculatura lisa foram descritos para diterpenos de $B$. trimera (Less) DC (Torres et al., 2000). Extratos e frações de $B$. trimera apresentaram resultados sugestivos de atividade antidiabética, como foi relatado por Oliveira et al. (2005).

Mendes et al. (2007) relatam que B. trimera apresentou uma moderada atividade antioxidante e não foi tão eficiente como antiúlcera em ratos (indução de úlceras por stress).

O presente estudo tem por finalidade avaliar a atividade antiúlcera da espécie Baccharis trimera Less (DC), pelo método de úlcera gástrica induzida através do etanol e ácido clorídrico, a atividade antioxidante pela reação com DPPH e a toxicidade aguda através de dose única.

\section{MATERIAL E MÉTODOS}

\section{Vegetal}

A espécie a ser estudada foi obtida de cultivo do Centro Pluridisciplinar de Pesquisas Químicas, Biológicas e Agronômicas, da UNICAMP. A exsicata recebeu a identificação 1.286 .

O extrato hidroalcoólico a $70 \%$ foi elaborado por percolação de acordo com a Farmacopéia Brasileira (1959). O fracionamento foi feito a partir do extrato bruto liofilizado tendo como extratores o clorofórmio, acetato de etila; etanol e etanol $50 \%$, sendo o solvente retirado para os ensaios.

\section{Atividade antiúlcera: modelo de indução aguda por etanol e ácido clorídrico}

O estudo foi aprovado pela Comissão de Ética em Experimentação Animal da Faculdade de Ciências Farmacêuticas da Universidade de São Paulo.

O teste de atividade antiúlcera aguda foi realizado com 3 grupos de animais, com peso médio de $180 \mathrm{~g}$, em jejum por 24 horas, somente com livre acesso a água. Foram administrados a ratos Wistar fêmeas por via oral água ( $1 \mathrm{ml} / 100 \mathrm{~g}$ de animal) sendo este o grupo controle negativo, ao grupo teste administrou-se o extrato liofilizado de $B$. trimera nas doses de 400, 200 e $100 \mathrm{mg} /$ $\mathrm{kg}$ ressuspenso em água, na concentração de $40 \mathrm{mg} /$ $\mathrm{ml}$, e ao grupo controle positivo foram administrados $30 \mathrm{mg} / \mathrm{kg}$ de lansoprazol.Como agente ulcerogênico foi administrado a todos os animais, após trinta minutos, uma solução de acido clorídrico 0,3 M em etanol a 60\% (1 $\mathrm{ml} / 100 \mathrm{~g}$ de animal). Ao final de 1 hora os animais foram mortos, os estômagos retirados, abertos pela curvatura maior, lavados com solução fisiológica e prensados entre placas de vidro (Mizui \& Doteuchi, 1983 e Matsumoto \& Yamada, 1991). A área das ulcerações foi medida através do programa Image Pro-Plus, sendo os valores expressos através da área total de lesões ulcerativas, em $\mathrm{mm}^{2}$ (ATL) calculada pela somatória das áreas de lesões individuais e através da área relativa de lesão (ARL), referente à porcentagem de área ulcerativa em relação à área total do estômago. Os resultados foram avaliados através de análise estatística ANOVA seguida de Tukey utilizando o programa GraphPad Instant 2.

\section{Atividade antioxidante}

A atividade antioxidante foi determinada pela reação com DPPH. Descrito inicialmente por Brand-Williams et al. (1995), esse método baseia-se na redução do radical 2,2'-difenil-1-picril-hidrazil (DPPH), apresentando máxima absorção em $517 \mathrm{~nm}$. Pode-se avaliar através da diminuição da absorbância, a presença de compostos capazes de doar hidrogênios ou seqüestrar o radical permitindo calcular a quantidade de antioxidante necessária para reduzir 50\% do DPPH após o equilíbrio da reação. Foi determinada uma curva de calibração da vitamina E, com cinco pontos. O percentual de atividade do DPPH foi calculado como segue (Mensor et al., 2001). 


$$
\% \text { de atividade }=100-\frac{100 \times \text { amostra }}{\text { Controle }}
$$

Foram calculados por regressão linear dos gráficos, os valores de EC50, onde a abscissa representa a atividade antioxidante (\%) das amostras de Baccharis trimera (Less) DC., resultante de três determinações e a ordenada, a concentração do extrato $(\mu \mathrm{g} / \mathrm{mL})$.

\section{Toxicidade aguda}

No ensaio de toxicidade aguda por dose única foram administrados por via oral $5 \mathrm{~g} / \mathrm{kg}$ do extrato bruto liofilizado de Baccharis trimera (Less) DC e $1 \mathrm{ml} / 100$ g de água (controle negativo) a camundongos machos e fêmeas. Foi observado o comportamento dos animais (agitação, irritabilidade, depressão, resposta ao toque, aperto de cauda, contorção, força de agarrar, tremores, respiração, convulsão, diarréia, constipação, alteração dos pelos, pele e mucosa). Foi verificado o número de mortos. O consumo de água e ração, bem como a massa

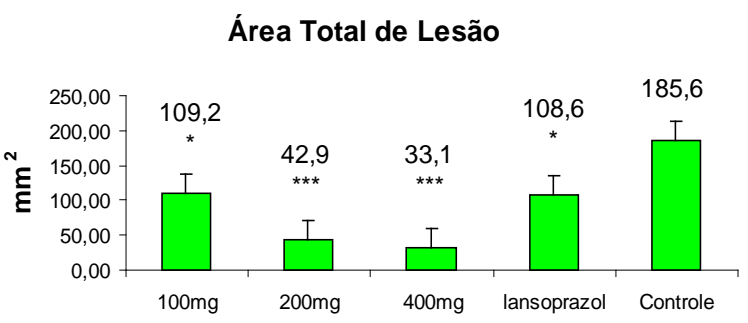

Figura 1. Área total de lesão no ensaio antiúlcera agudo através do modelo de indução por ácido clorídrico 0,3 M em etanol a $60 \%$ após a administração oral de água (controle), $30 \mathrm{mg} / \mathrm{kg}$ de lansoprazol, $100 \mathrm{mg} / \mathrm{kg}, 200 \mathrm{mg} / \mathrm{kg}$ e $400 \mathrm{mg} / \mathrm{kg}$ de extrato bruto de $B$. trimera. Os valores estão expressos como a média \pm erro padrão. $\mathrm{n}=7$.*** $\mathrm{p}<0,001 ; * \mathrm{p}<0,05$.

\section{Área Relativa de Lesão}

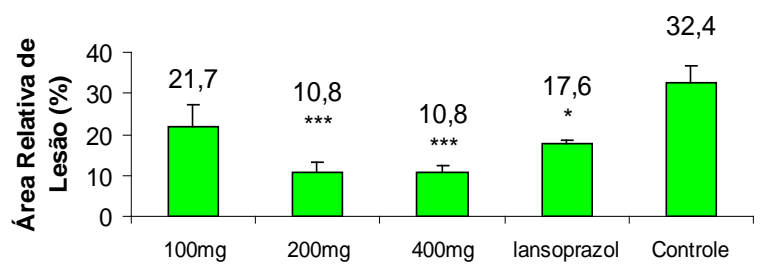

Figura 2. Área total de lesão no ensaio antiúlcera agudo através do modelo de indução por ácido clorídrico $0,3 \mathrm{M}$ em etanol a $60 \%$ após a administração oral de água (controle), $30 \mathrm{mg} / \mathrm{kg}$ de lansoprazol, $100 \mathrm{mg} / \mathrm{kg}, 200 \mathrm{mg} / \mathrm{kg}$ e $400 \mathrm{mg} / \mathrm{kg}$ de extrato bruto de $B$. trimera. Os valores estão expressos como a média \pm erro padrão. $\mathrm{n}=7$. $* * * \mathrm{p}<0,001 ; * \mathrm{p}<0,05$. corpórea dos animais, foram determinados a cada dois dias, por 14 dias. Ao final de 14 dias foi realizada a análise macroscópica dos órgãos (coração/pulmão, fígado e rins) dos camundongos machos e fêmeas, e verificada sua massa (Brito, 1994).

\section{Análise estatística}

Os resultados foram expressos como a média mais ou menos o desvio padrão. Foi usado para comparar mais que duas amostras "One-way" análise de variância (ANOVA) de acordo com Runyon e Haber 1984, com intervalo de confiança de $\mathrm{p}<0,05$ (Mensor et al., 2001). A significância entre os pares de amostras foi verificada através do teste de Tukey.

\section{RESULTADOS}

Os resultados das avaliações indicam que 0 extrato bruto liofilizado, administrado na dose de 400 $\mathrm{mg} / \mathrm{kg}$, reduziu em $90 \%$ a área de lesão, $\mathrm{P}<0,001(* * *)$, $200 \mathrm{mg} / \mathrm{kg}$ reduziu em $87 \%$ a área de lesão, $\mathrm{P}<0,001$

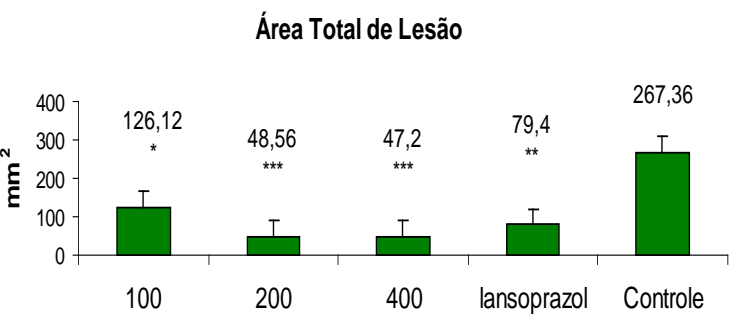

Figura 3. Área total de lesão no ensaio antiúlcera agudo através do modelo de indução por ácido clorídrico 0,3 $\mathrm{M}$ em etanol a $60 \%$ após a administração oral de água (controle), $30 \mathrm{mg} / \mathrm{kg}$ de lansoprazol, $100 \mathrm{mg} / \mathrm{kg}, 200 \mathrm{mg} / \mathrm{kg}$ e $400 \mathrm{mg} / \mathrm{kg}$ de extrato liofilizado da "resina" de $B$. trimera. Os valores estão expressos como a média \pm erro padrão. $\mathrm{n}=7$. ${ }^{* * *} \mathrm{p}<0,001$; ${ }^{* *} \mathrm{p}<0,01$; $* \mathrm{p}<0,05$.

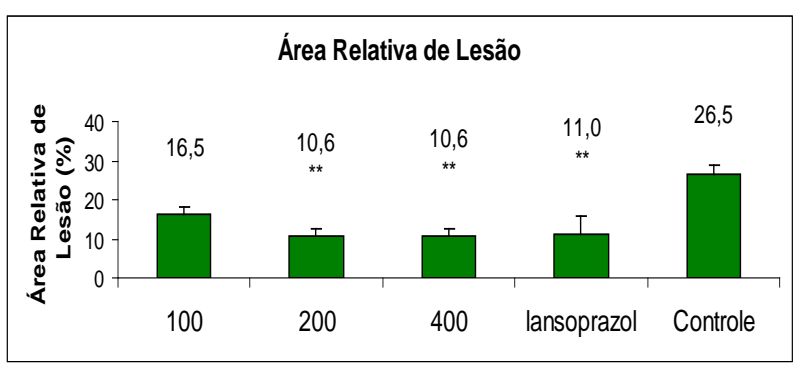

Figura 4. Área total de lesão no ensaio antiúlcera agudo através do modelo de indução por ácido clorídrico 0,3 $\mathrm{M}$ em etanol a $60 \%$ após a administração oral de água (controle), $30 \mathrm{mg} / \mathrm{kg}$ de lansoprazol, $100 \mathrm{mg} / \mathrm{kg}, 200 \mathrm{mg} / \mathrm{kg}$ e $400 \mathrm{mg} / \mathrm{kg}$ de extrato liofilizado da "resina" de $B$. trimera. Os valores estão expressos como a média \pm erro padrão. $\mathrm{n}=7$.*** $\mathrm{p}<0,001 ; * \mathrm{p}<0,05$. 
Tabela 1. Atividade antioxidante (\%), do pó da droga, extrato bruto liofilizado, extrato bruto liofilizado da "resina", frações clorofórmica, acetato de etila, etanol absoluto e etanol 50\% de B.trimera, frente ao DPPH.

\begin{tabular}{|c|c|c|}
\hline Amostra & $\begin{array}{c}\text { Concentração da amostra } \\
(\mu \mathrm{g} / \mathrm{mL})\end{array}$ & $\begin{array}{c}\text { Atividade Antioxidante } \\
\text { (\%) }\end{array}$ \\
\hline Pó da droga & 25 & $52,29 \pm 2,27 \times 10^{-2}$ \\
\hline Pó da droga & 20 & $44,54 \pm 1,06 \times 10^{-2}$ \\
\hline Pó da droga & 15 & $36,67 \pm 1,60 \times 10^{-2}$ \\
\hline Pó da droga & 10 & $27,37 \pm 1,05 \times 10^{-2}$ \\
\hline Pó da droga & 5 & $12,46 \pm 2,86 \times 10^{-2}$ \\
\hline Extrato bruto liofilizado & 25 & $56,42 \pm 1,00 \times 10^{-2}$ \\
\hline Extrato bruto liofilizado & 20 & $45,32 \pm 1,60 \times 10^{-2}$ \\
\hline Extrato bruto liofilizado & 15 & $36,22 \pm 1,45 \times 10^{-2}$ \\
\hline Extrato bruto liofilizado & 10 & $26,86 \pm 1,05 \times 10^{-2}$ \\
\hline Extrato bruto liofilizado & 5 & $13,43 \pm 2,30 \times 10^{-2}$ \\
\hline Extrato bruto liofilizado da "resina" & 25 & $58,17 \pm 1,65 \times 10^{-2}$ \\
\hline Extrato bruto liofilizado da "resina" & 20 & $41,96 \pm 1,95 \times 10^{-2}$ \\
\hline Extrato bruto liofilizado da "resina" & 15 & $27,05 \pm 1,95 \times 10^{-2}$ \\
\hline Extrato bruto liofilizado da "resina" & 10 & $18,27 \pm 1,05 \times 10^{-2}$ \\
\hline Extrato bruto liofilizado da "resina" & 5 & $5,49 \pm 1,10 \times 10^{-2}$ \\
\hline Fração clorofórmica & 25 & $53,71 \pm 1,44 \times 10^{-2}$ \\
\hline Fração clorofórmica & 20 & $39,64 \pm 1,93 \times 10^{-2}$ \\
\hline Fração clorofórmica & 15 & $31,12 \pm 2,10 \times 10^{-2}$ \\
\hline Fração clorofórmica & 10 & $22,92 \pm 1,08 \times 10^{-2}$ \\
\hline Fração clorofórmica & 5 & $12,46 \pm 1,78 \times 10^{-2}$ \\
\hline Fração acetato de etila & 25 & $55,46 \pm 1,51 \times 10^{-2}$ \\
\hline Fração acetato de etila & 20 & $42,41 \pm 1,00 \times 10^{-2}$ \\
\hline Fração acetato de etila & 15 & $30,41 \pm 2,00 \times 10^{-2}$ \\
\hline Fração acetato de etila & 10 & $24,98 \pm 2,10 \times 10^{-2}$ \\
\hline Fração acetato de etila & 5 & $12,98 \pm 2,80 \times 10^{-2}$ \\
\hline Fração etanol absoluto & 25 & $68,11 \pm 2,02 \times 10^{-2}$ \\
\hline Fração etanol absoluto & 20 & $58,55 \pm 1,25 \times 10^{-2}$ \\
\hline Fração etanol absoluto & 15 & $46,42 \pm 1,00 \times 10^{-2}$ \\
\hline Fração etanol absoluto & 10 & $31,05 \pm 2,06 \times 10^{-2}$ \\
\hline Fração etanol absoluto & 5 & $17,69 \pm 1,50 \times 10^{-2}$ \\
\hline Fração etanol 50\% & 25 & $69,79 \pm 1,04 \times 10^{-2}$ \\
\hline Fração etanol 50\% & 20 & $55,91 \pm 1,88 \times 10^{-2}$ \\
\hline Fração etanol 50\% & 15 & $38,22 \pm 1,00 \times 10^{-2}$ \\
\hline Fração etanol 50\% & 10 & $27,63 \pm 1,50 \times 10^{-2}$ \\
\hline Fração etanol 50\% & 5 & $13,04 \pm 1,77 \times 10^{-2}$ \\
\hline
\end{tabular}

Tabela 2. Atividade antioxidante (\%) da Vitamina E, frente ao DPPH.

\begin{tabular}{cc}
\hline $\begin{array}{c}\text { Concentração da amostra } \\
(\mu \mathrm{g} / \mathrm{mL})\end{array}$ & $\begin{array}{c}\text { Atividade Antioxidante } \\
(\%)\end{array}$ \\
\hline 25 & $68,83 \pm 2,00 \times 10^{-2}$ \\
20 & $55,33 \pm 2,00 \times 10^{-2}$ \\
15 & $45,59 \pm 0,00 \times 10^{-2}$ \\
10 & $34,52 \pm 0,00 \times 10^{-2}$ \\
5 & $23,34 \pm 1,00 \times 10^{-2}$ \\
\hline
\end{tabular}

(***), $100 \mathrm{mg} / \mathrm{kg}$ reduziu em 66\% a área de lesão, $\mathrm{P}<$ 0,05 (*) e o fármaco controle (lansoprazol) reduziu a área de lesão em 66\%, P < 0,05 (*). O extrato liofilizado da "resina” (porção que durante a concentração dos extratos ficava depositada no fundo do recipiente apresentando um aspecto viscoso e pegajoso), administrado na dose de
$400 \mathrm{mg} / \mathrm{kg}$, reduziu a área de lesão em 82\%, P < 0,001 (***), $200 \mathrm{mg} / \mathrm{kg}$ reduziu em 82\% a área de lesão, $\mathrm{P}<$ 0,001 (***), $100 \mathrm{mg} / \mathrm{kg}$ reduziu em 53\% a área de lesão, $\mathrm{P}<0,05$ (*) e o fármaco controle (lansoprazol) reduziu a área de lesão em 70\%, P <0,01 (**). (ver Figuras 1 a 4) 


\section{Atividade antioxidante}

Os resultados de atividades antioxidante estão apresentados nas Tabelas 1 e 2 .

\section{Toxicidade aguda}

Foi observado o comportamento dos animais, o consumo de água e ração, a massa corpórea a cada dois dias, não havendo alteração significativa em relação ao controle. Ao final de 14 dias foi realizada a análise macroscópica dos órgãos (coração/pulmão, fígado e rins) não tendo sido observada nenhuma alteração aparente em relação ao controle. A massa dos órgãos dos animais machos e fêmeas, tanto do grupo tratado como do grupo controle, foi determinada ao final do experimento, não tendo sido observada nenhuma alteração significativa.

\section{DISCUSSÃO}

A úlcera é uma lesão do revestimento da mucosa gástrica (Mizui \& Doteuchi, 1983; Falcão et al., 2008a,b). Já a úlcera péptica gastroduodenal é uma doença que resulta da perda circunscrita de tecido da mucosa, podendo ocorrer nas regiões do trato digestivo que entram em contato com a secreção ácida do estômago (Lüllmann et al., 1993).

A etiologia da úlcera gástrica ainda não está totalmente elucidada. Fato conhecido é que há um desequilíbrio entre os fatores agressivos (secreção de ácido e pepsina) e os fatores citoprotetores como secreção de bicarbonato, secreção de muco e produção de prostaglandinas (Brunton, 1996). Destacam-se também como fatores agressivos o excesso de álcool, antiinflamatórios não esteroidais, estresse (Rang et al., 2004), síndrome de Zollinger-Ellison, que é um tumor pancreático estimulador da produção de gastrina (Lüllmann et al., 1993).

A verificação da atividade antiúlcera do extrato bruto liofilizado de Baccharis trimera (Less) DC foi realizada utilizando modelo de indução aguda por etanol acidificado, que avalia, entre outras, a atividade de substâncias citoprotetoras (Mizui \& Doteuchi, 1983; Matsumoto \& Yamada, 1991). O etanol produz lesões necróticas na mucosa gástrica, reduzindo a secreção de bicarbonato e a produção de muco, além de modificar sua composição de glicoproteínas (Marhuenda et al., 1993). A indução da lesão gástrica pelo etanol ou pelo etanol acidificado ocorre devido a redução do fluxo sangüíneo na mucosa gástrica, seguida de estase sangüínea, que contribui para o desenvolvimento de hemorragias e necrose de tecidos (Guth, 1984). A presença de ácido clorídrico somente acelera e agrava este processo (Mizui \& Doteuchi, 1983).

No modelo utilizado, o extrato bruto liofilizado de Baccharis trimera (Less) DC apresentou valores significativos em comparação ao grupo controle reduzindo em aproximadamente $90 \%$ a área total de lesão ulcerativa, e o extrato liofilizado da "resina" reduziu em $82 \%$, porém não houve variação significativa entre o extrato liofilizado e a "resina". Observou-se também que nas concentrações de $400 \mathrm{mg} / \mathrm{kg}$ e $200 \mathrm{mg} / \mathrm{kg}$ do extrato bruto liofilizado as reduções da área total de lesão apresentaram-se muito próximas, assim como do extrato liofilizado da "resina". Estes resultados indicam que relação dose-efeito provavelmente ocorre abaixo de 400 $\mathrm{mg} / \mathrm{kg}$, uma vez que não houve diferença aparente acima de $200 \mathrm{mg} / \mathrm{kg}$.

Uma substância antioxidante é aquela que inibe o processo de oxidação, e assim protege os sistemas biológicos contra os efeitos danosos de processos ou reações que promovem a oxidação de macromoléculas ou estruturas celulares (Abdala, 1996). Antioxidantes geralmente são compostos fenólicos ou aminas aromáticas, como $\alpha$-tocoferol, flavonóides e vários antioxidantes sintéticos (Larson, 1988; Abdala, 1996; Shoeb et al., 2007; Vicentino \& Menezes, 2007). Em nossos experimentos a atividade antioxidante foi detectada através do reativo 2,2'-difenil-1-picril-hidrazil (DPPH). A vantagem deste método é a possibilidade do ensaio com grande número de amostras, em curto período de tempo, sendo suficientemente sensível para detectar princípios ativos em baixas concentrações (Yokozawa et al., 1998).

Relativo à atividade antioxidante, o pó da droga (D), o extrato bruto liofilizado (EBL), extrato bruto liofilizado da "resina" (EBLR) e frações clorofómica, acetato de etila, etanol absoluto e etanol 50\% de Baccharis trimera (Less) DC, apresentaram $\mathrm{EC}_{50} 22,74 \mu \mathrm{g} / \mathrm{mL}$, $21,83 \mu \mathrm{g} / \mathrm{mL}, 22,6 \mu \mathrm{g} / \mathrm{mL}, 24,93 \mu \mathrm{g} / \mathrm{mL}, 23,05 \mu \mathrm{g} / \mathrm{mL}$, $17,18 \mu \mathrm{g} / \mathrm{mL}, 18,19 \mu \mathrm{g} / \mathrm{mL}$, respectivamente, sendo $\mathrm{EC}_{50}$ da vitamina E, $16,71 \mu \mathrm{g} / \mathrm{mL}$. Comparando os resultados das amostras com os do padrão de vitamina E, podemos sugerir atividade antioxidante bastante evidente. No trabalho de Mendes et al. (2007), o resultado do $\mathrm{EC}_{50}$ de $B$. trimera foi $7,76 \mu \mathrm{g} / \mathrm{mL}$ e o modelo por eles utilizado foi de lipoperoxidação em cérebro de rato. Nesse mesmo trabalho os autores verificaram reduzida atividade antiúlcera em ratos, induzida por estresse.

Não houve sinais de toxicidade aguda no modelo ensaiado, sendo necessários estudos em outros modelos, para comprovação da atividade e da baixa toxicidade.

\section{REFERÊNCIAS}

Abdala DSP 1996. Radicais livres e antioxidantes. In: Oga, S. Fundamentos de toxicologia. São Paulo: Atheneu. cap. 1.4, p. 37-58.

Agra MF, França PF, Barbosa-Filho JM 2007. Synopsis of the plants known as medicinal and poisonous in Northeast of Brazil. Rev Bras Farmacogn 17: 114-140.

Agra MF, Silva KN, Basílio IJLD, França PF, Barbosa-Filho JM 2008. Survey of medicinal plants used in the region Northeast of Brazil. Rev Bras Farmacogn 18: 472508. 
Baggio CH, Freitas CS, Rieck L, Marques MCA 2003. Gastroprotective effects of a crude extract of Baccharis illinita DC in rats. Pharmacol Res 47: 93-98.

Biavatti M, Marensi V, Leite SN, Reis A 2007. Ethnopharmacognostic survey on botanical compendia for potential cosmeceutic species from Atlantic Forest. Rev Bras Farmacogn 17: 640-653.

Borella JC, Duarte DP, Novaretti AAG, Menezes Jr A, França SC, Rufato CB, Santos PAS, Veneziani RCS, Lopes NP 2006. Variabilidade sazonal do teor de saponinas de Baccharis trimera (Less.) DC (Carqueja) e isolamento de flavona. Rev Bras Farmacogn 16: 557-561.

Brand-Williams W, Cuvelier ME, Berset C 1995. Use of a free radical method to evaluate antioxidant activity. Lebensm-Wiss Technol 28: 25-30.

Brito AS 1994. Manual de ensaios toxicológicos in vivo. Campinas: Unicamp.

Brunton LL 1996. Fármacos para controle da acidez gástrica e tratamento de úlceras pépticas. In: Hardman JG, Limberd LE, Molinoff PB, Ruddon RW, Gilman AG (eds.) Goodman \& Gilman as bases farmacológicas da terapêtica. 9.ed. Rio de Janeiro: McGraw-Hill, p.663-674.

Falcão HS, Mariath IR, Diniz MFFM, Batista LM, BarbosaFilho JM 2008a. Plants of the American continent with antiulcer activity. Phytomedicine 15: 132-146.

Falcão HS, Leite JA, Barbosa-Filho JM, Athayde-Filho PF, Chaves MCO, Moura MD, Ferreira AL, Almeida ABA, Souza-Brito ARM, Diniz MFFM, Batista LM 2008b. Gastric and duodenal antiulcer activity of alkaloids: a review. Molecules 13: 3198-3223.

Farmacopéia dos Estados Unidos do Brasil. 1959. 2.ed. São Paulo: Indústria Gráfica Siqueira, 1265p.

Gamberini MT, Skorupa LA, Souccar C, Lapa AJ 1991. Inhibition of gastric secretion by a water extract from Baccharis triptera, Mart. Mem Inst Oswaldo Cruz 86 (Suppl. 2): 137-139.

Gene RM, Cartarana C, Adzet T 1992. Anti-inflammatory effect of aqueous extracts of three species of the genus Baccharis. Planta Med 58: 565-566.

Gene RM, Cartarana C, Adzet T, Marin E, Parella T, Canigueral S 1996. Anti-inflamatory and analgesic activity of Baccharis trimera: identification of its active constituents. Planta Med 62: 232-235.

Guth PH 1984. Histologic and microcirculatory changes in alcohol- induced gastric lesions in the rat: effect of prostaglandin cytoprotection. Gastroenterology 87: 1083-1090.

Jakupovic J 1990. Sequi and diterpenes from Baccharis species. Phytochemistry 29: 2217-2222.

Larson RA 1988. The antioxidantes of higher plants. Phytochemistry 27: 969-978.

Lorenzi H, Matos FJA 2002. Plantas medicinais no Brasil: nativas e exóticas. Nova Odessa: Instituto Plantarum.

Lullmann H, Mohr K, Ziegler A, Bieger D 1993. Color Atlas of Pharmacology. New York: Thieme Medical Publishers, 369 p.

Marhuenda E, Martin MJ, Alarcon de la Lastra C 1993. Antiulcerogenic activity of aescine in different experimental models. Phytother Res 7: 13-16.

Matsumoto T, Yamada H 1991. Effects of a polyssacaride fraction from the roots of Bupleurum falacatum $\mathrm{L}$. on experimental gastric ulcer models in rats and mice. $J$ Pharm Phamacol 43: 699-704
Mello JCP, Petrovick PR 2000. Quality control of Baccharis trimera (Less.) DC .(Asteraceae) hydroalcoholic extracts. Acta Farm Bonaerense 19: 211-215.

Mendes FR, Tabach R, Carlini EA 2007. Evaluation of Baccharis trimera and Davilla rugosa in tests for adaptogen activit. Phytother Res 21: 517-522.

Mensor LL, Menezes FS, Leitão GG, Reis AS, Santos TC, Coube CS, Leitão SG 2001. Screening of Brazilian plant extracts for antioxidant activity by the use of DPPH free radical method. Phytother Res 15: 127130.

Mizui T, Doteuchi M 1983. Effect of polyamines on acidified ethanol-induced gastric lesion in rats. Jpn J Pharmacol 33: 939-945.

Nakasugi T, Komai K 1998. Antimutagens in the Brazilian folk medicinal plant carqueja (Baccharis trimera Less.). $J$ Agric Food Chem 46: 2560-2564.

Oliveira AC, Endringer DC, Amorim LA, Das Graças LBM, Coelho MM 2005. Effect of the extracts and fractions of Baccharis trimera and Syzygium cumini on glycaemia of diabetic and non-diabetic mice. $J$ Ethnopharmacol 102: 465-469.

Queiroga ML, Ferracine VF 1996. Three new oxigenated cardinanes from Baccharis species. Phytochemistry 42: 1097-1103.

Rang HP, Dale MM, Ritter JM, Moore PK 2004. Farmacologia. 5.ed. Rio de Janeiro: Elsevier, p.419-433.

Ruiz ALTG, Taffarello D, Souza VHS, Carvalho JE 2008. Farmacologia e toxicologia de Peumus boldus e Baccharis genistelloides. Rev Bras Farmacogn 18: 295-300.

Shoeb M, MacManus SM, Jaspars M, Kong-Thoo-Lin P, Nahar L, Celik S, Sarker SD 2007. Bioactivity of two Turkish endemic Centaurea species, and their major constituents. Rev Bras Farmacogn 17: 155-159.

Simões-Pires CA, Queiroz F, Henriques AT, Hostettmann $\mathrm{K}$ 2005. Isolation and on-line identification of antioxidant compounds from three Baccharis species by HPLC-UV-MS/MS with post-column derivatisation. Phytochem Analysis 16: 307-314.

Silva FG, Januário AH, Pinto JEBP, Nascimento VE, Barizan WS, Sales JF, Franca SC 2006. Flavoid content in native and cultivated populations of "carqueja" [Baccharis trimera (Less.) DC.] harvested at dry and humid season. Rev Bras Pl Med 8: 19-25.

Soicke H, Leng-Peschlow E 1987. Characterisation of flavonóides from Baccharis trimera and their antihepatotoxic properties. Planta Med 53: 37-39.

Torres LM, Gamberini MT, Roque NF, Lima-Landman MT, Souccar C, Lapa AJ 2000. Diterpene from Baccharis trimera with a relaxant effect on rat vascular smooth muscle. Phytochemistry 55: 617-619.

Verdi LG, Brighente IMC, Pizzolatti MG 2005. Gênero Baccharis (Asteraceae): aspectos químicos, econômicos e biológicos. Quim Nova 28: 85-94.

Vicentino ARR, Menezes FS 2007. Atividade antioxidante de tinturas vegetais, vendidas em farmácias com manipulação e indicadas para diversos tipos de doenças pela metodologia do DPPH. Rev Bras Farmacogn 17: 384-387.

Yokozawa T, Chen CP, Dong E, Tanaka T, Nonaka GI, Nishioka I 1998. Study on the inhibitory effect of tannins and flavonoids against the 1,1-diphenyl-2-picrylhydrazyl radical. Biochem Pharmacol 56: 213-222. 